\title{
End of cold fusion in sight
}

Although the evidence now accumulating does not prove that that original observations of cold fusion were mistaken, there seems no doubt that cold fusion will never be a commercial source of energy.

IT seems the time has come to dismiss cold fusion as an illusion of the past four months or so. At the outset, on 23 February, the suggestion that deuterium nuclei can be made to fuse together at ordinary temperatures, if in exceptional circumstances, seemed a brave leap of the imagination. The article on page 29 of this issue by M. Gai et al. of Yale University is merely another nail in the coffin of the idea. The Yale group has done its best to replicate the conditions of the original experiments, but has failed to replicate their results. Similar outcomes have been reported from other laboratories. So what has been learned from these hectic months?

First, the negative results now being reported do not imply that the original observations by Stanley Pons and Martin Fleischmann at the University of Utah and by Stephen E. Jones and his colleagues at the Brigham Young University were grossly mistaken. Events may yet show that there are circumstances in which palladium electrodes in electrolytic cells emit pulses of neutrons just as they would if deuterium nuclei were fusing together; early this month, a group at the Los Alamos National Laboratory was wondering what to make of such an observation.

So far, all that is clear is that the original reports do not conceal a recipe for making large (Utah) or even modest (Brigham Young) amounts of power by deuterium fusion. For the many non-scientists who have been excited by the past few weeks, this will be a disappointment. By the same test, the managers of orthodox experiments intended to replicate what happens within the Sun will be relieved.

One striking feature of these events is that, even now, those who have been trying to replicate the original findings are remarkably good-humoured about the time and energy they have spent. Those concerned seem to have found it an inherently interesting exercise. It is not, after all, every day that they find themselves worrying about electrochemistry and nuclear physics at the same time. And it is interesting to have been reminded at first hand of the remarkable capacity of palladium and titanium to dissolve hydrogen, usually known only from books and journals. Moreover, the brief spell in April when it seemed as if cold fusion would permanently divide chemists and physicists has left no trace.

All of us, even bystanders, have also learned a great deal about the difficulty of counting absolute numbers of neutrons and of $\gamma$-rays. The argument between Richard Petrasso and his colleagues at MIT on the one hand and Pons and Fleishmann on the other about the $\gamma$-ray measurements have been for many people educative, to say the least. Petrasso and his colleagues (Nature 339, 183; 1989) first complained of inconsistencies in the only published report by Pons and Fleischmann of their observations, were given an incomplete reply (Nature 339, 667; 1989), but on that basis were able to argue (Nature 339, 667; 1989) that the energy channels in the original equipment had probably been miscalibrated and that the energy spectrum is narrower than the resolution of the $\gamma$-ray detector would allow.

There is even doubt about the placing of the $\gamma$ line purportedly resulting from neutron emission which has been variously reported as at $2.2 \mathrm{MeV}$ and at $2.5 \mathrm{MeV}$. Pons and Fleischmann originally put it at $2.2 \mathrm{MeV}$, which is what would be expected if the $\gamma$-rays come from the conversion of neutrons in water. But now, in their reply to Petrasso, they say they could not have measured such a peak at such an energy, but that it is in any case at $2.5 \mathrm{MeV}$ (which Petrasso disputes on calibration grounds). The best resolution of this dispute would be by independent measurement, but that seems unlikely while attempts to replicate the phenomenon as a whole are unsuccessful. Meanwhile, there will be many who consider the $\gamma$-ray signal to have been an artefact.

That point is nevertheless crucial to the unfolding of events after 23 February, when both The Wall Street Journal and The Financial Times published long accounts of what had been done at Utah and when the University of Utah held a press conference to tell the wider world. (Nature owes Pons and Fleischmann an apology for having reported that, on that occasion, they had said that their formal paper had been sent to this journal for publication.)

It is unthinkable that reports of the production of excess heat in such complicated electrochemical cells would, by itself, have been seriously regarded as proof of deuterium fusion. Only the measurement of nuclear particles and products, with the expected energy, could have commanded the interest since shown. Pons and Fleischmann now say that "as we have repeatedly pointed out, we are well aware of the deficiencies of these spectra", but there are no records of that reservation earlier than the meeting of the US Electrochemical Society at Los Angeles, by which time they had been sent (but may not have read) Petrasso's first draft of his complaint. This is a more serious retreat than they acknowledge.

None of this implies that Pons and Fleischmann have been anything but straightforward. Put yourself in their position if you believe otherwise. If, on 23 February, you had made such an arresting announcement that the whole world was agog, even picking up the telephone would probably engage you in a half-hour conversation with somebody you had never met. Your compelling interest, to gather more data, would be compromised by the inquisitiveness of people asking elementary questions about issues then, in your mind, settled. It is remarkable that Pons and Fleischmann, with all the pressure on them, should have been able to cover so much ground.

So how should they, in the contemporary argot, have played it? It is too easy to say that they should never have given the story of their doings to the financial newspapers, or have allowed a press conference to be held on their behalf. The conventional wisdom, that they should have sent an account of their work to a respectable science journal and then have put themselves in the hands of its referees and editors, is too bland. If people believe they have found a way of changing the world, why should they not tell the world what is in store in their own way?

But there are obvious dangers in such a course, of which the chief is that one may be mistaken. Ordinarily, there is no shame in that: people make mistakes all the time. Ordinarily, there are also colleagues to point to pitfalls in one's path, but potential sceptics may on this occasion have been denied access by the care with which the project was kept secret over five years. It is less easy to accept that one may afterwards be required to accept irksome conditions on how one practises research by an over-confident university; from about 24 February, Pons and Fleischmann might well have decided that they should put their responsibility to the scientific community before that to the organizer of their press conference. Even now, it would be interesting if they made their data generally available, whatever its correct interpretation.

John Maddox 